\title{
IPAD AS ASSISTIVE TECHNOLOGY IN EDUCATION
}

\author{
Vojtěch Gybas ${ }^{1}$, Libor Klubal ${ }^{2}$ and Kateřina Kostolányová ${ }^{3}$ \\ University Of Ostrava, Pedagogical Faculty, Department of Information and Communication Technologies \\ Fráni Šrámka 3, Ostrava, Mariánské Hory, 70900, Czech Republic \\ ${ }^{l} M g r ., P h . D$. \\ ${ }^{2} \mathrm{Mgr}$. \\ ${ }^{3}$ Doc. Ing., Ph.D.
}

\begin{abstract}
According to the currently valid school legislation, pupils with special educational needs can be educated in basic schools of a common type. Until 2016, special schools were designated for these pupils who were diagnosed of mental retardation in a moderate range as their primary handicap. Newly, so-called inclusive school environment enables to join these pupils into basic school education. Nevertheless, many such pupils are educated in special primary schools, where there are the optimal conditions for their development, and these schools are equipped with adequate special pedagogical materials. However, special educators are becoming increasingly aware of ICT. Specifically, iPads. This paper describes a case study of a successful iPad implementation into the pupil's education at a special elementary school. At the same time, the contribution is devoted to the description of the expected outputs according to the valid framework educational program for the special primary education.
\end{abstract}

\section{KEYWORDS}

Special School, iPad, Case Study, Assisted Access

\section{INTRODUCTION}

Using iPads with pupils in elementary schools carries risks. One of these risks may be pupil's distraction, who is unable to work with the iPad then. By activating iPad Assisted Access, we can greatly reduce pupil's distraction and increase workload.

\section{IPAD AS ASSISTIVE TECHNOLOGY}

Assistive technology can help students overcome the mechanical aspects of writing skill. Using spell-check and grammar, students can concentrate on expressing their ideas, and students can write with confidence, knowing they can easily make changes. In addition, they are able to present their final work, which is clearer and better organized (Batorowicz, Missiuna, \& Pollock, 2012). The results of the iPad support study for mothers and their preschool children show that the iPad-enabled assistive technologies in the settings / accessibility tab are applied to pupils with SEN in numerous areas such as reading, writing, communication, day-to-day structure, etc. (Aram \& Bar-Arm, 2016; Batorowicz, Missiuna, \& Pollock, 2012). The iPad in Education (2012) study adds that introducing the iPad into special education is a step forward. A field study in selected European countries concluded that the iPad, thanks to its ability to access, significantly supports individualized learning that was highlighted as a major benefit of pupils' work with this device. Above all, the ability to control the iPad only visually is highlighted in a case study from Belgium where the iPad is controlled by a SEN pupil who cannot move the upper and lower limbs (SENnett, 2014). IPad access can be used in a variety of ways to suit individual pupils, including those who cannot rely on fingertip control and use other parts of the body (nose, joint finger flexion, etc.). Pupils can control applications that do not require a precise touch and are able to work with the iPad (Flewitt, Kucirkova \& Messer, 2014); making accessibility helps to increase the independence of pupils with mental disabilities and helps them to acquire skills in the learning process (Flores, Musgrove, Renner, Hinton, Strozier, Franklin \& Hill, 2012). 


\section{ASSISTED ACCESS}

Assisted approach helps students with autism, attention deficit disorder and mental disabilities to concentrate better and stay on task. For parents or educators it is a way to "block" pupils into the app by preventing them from tapping the Home Button. This function will help pupils with SEN to be focused only on assigned tasks. The managed approach allows parents and educators to "restrict the touch functionality of certain parts of the screen," which is a very useful feature when pupils begin their work or finish a task on the iPad. Among the factors that can disrupt MDZ work and which can be minimized by assisted access, we rank (Gybas, online, 2017):

- control of an iPad that is unwanted (wrong home button press etc.),

- unwanted, unnecessary manipulation with the iPad.

- inconsistency in the work environment of the application,

- deliberate disturbance of work.

\subsection{Scheme of Assisted Access Functionality}

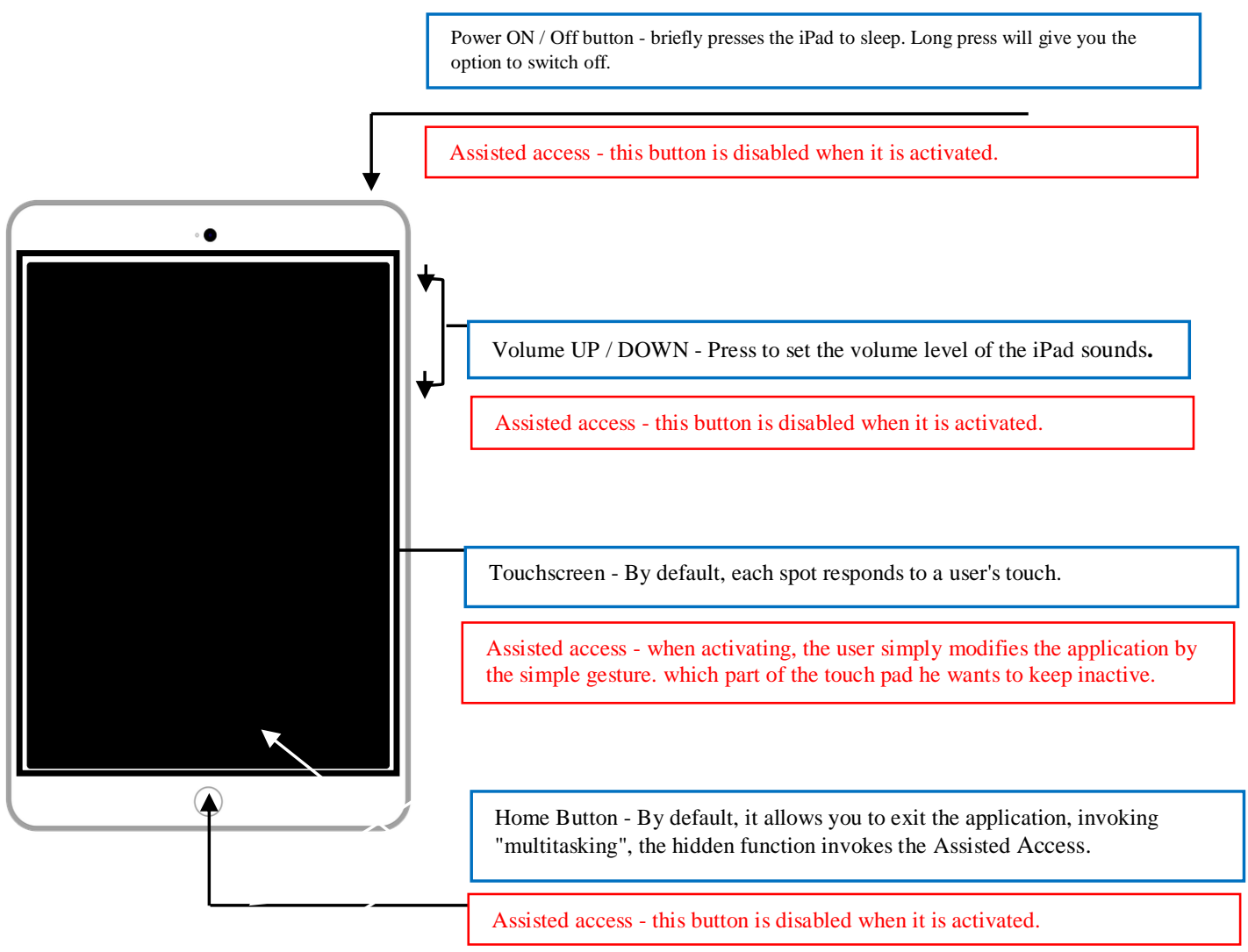




\section{CASE STUDY}

\author{
Student \\ Year of Birth \\ Age \\ Sex \\ Start of compulsory education
}

\author{
Educational program
}

V.B.

2003

15

Female

2010

"SPOLU" program for the elementary school Special education (hereinafter "SPOLU"), according to the valid Framework Educational Program for Special Secondary School Education-Part 2 - Education of pupils with severe mental disabilities and concurrent disability with multiple defects ZSS)

Moderate mental retardation, $\mathrm{ADD}$, Paroxysmal syndrome

\subsection{Initial State}

$\mathrm{V}$ is the younger of two siblings, and she is the one who has a diagnosis of mental retardation. The elder brother has no mental deficiency, currently studying University. Mother suffered pneumonia during pregnancy. Subsequent medication, as well as her age (38) probably influenced the current state of V. V. commutes to school every day with her mother. She is not able to get to school by herself. Btw. she is different from other pupils by the fact that she is relatively above-standard communicative in terms of quantity. She literally does not shut her mouth. She constantly comments on something, asks questions all the time. Her communicative speech is specific, sometime inappropriate, but it can be apologized at the situation. For example, when her class teacher records marks in a pupil's book, she says: "Teacher, do not you do anything again? I thought so. "I laughed for the first time. And it was not the last time. Watching the class teacher and his reaction to her comments was really boring, he responded as if they were normal, just a part of conversation of two people. But what was really fun to watch V. commenting things with such enthusiasm, especially what comment will come out of her mouth this time. Sometimes I said, now it's too much. But nothing. The teacher reacted as nothing happened again. With both gross and fine motor skills, V is very poor. The observation showed that the movement of her body was very clumsy, she was unbalanced, she was leaning to the left. She often even stumbles on the flat floor and falls. Balancing problems are the most common when changing position from standing to sitting. It is necessary to watch her when she is holding her chair and sitting down. The chair is optionally set at the lowest possible position. This is the only way to eliminate falls that occurs by wiggling and sitting on the edge of the chair despite the fact that the sitting area is very wide. Her whole movement is accompanied by her constant trembling palms, which is visible when V. wants to grab something - her bag, mug, towel, etc. Here is a very noticeable complex muscle weakness and total weakness. Fine motor skill is poorly developed due to her diagnosis. All this means that she is not capable of cutting, manipulating with small items, etc. With regard to self-service, there are activities that such affected pupil should deal with by herself; such as basic hygienic habits, to have a snack, to give the teacher a textbook, a pupil's book, etc. Here is a contradiction in the perception of individual acts. As far as the tasks related to the aids are concerned, V. is relatively clever and understands very well what she wants. "V. please give me your report book." "Jesus... OK" replies. She looks at the teacher as he is her best friend, with serious expression in her face that is the best for this situation from her point of view. While passing the report book, she accompanies it with words "Vojto!, I brought you the report book, here, here, here you are, Vojto, here it is, am I cute? She asks with a smile. It looks as if she has walked a long way, but it's about $2.5 \mathrm{~m}$ away to the teacher's position. But the teacher appreciates it because, despite the possible risks of falling, $\mathrm{V}$ is trying to increase the feeling of satisfaction, the feeling of success, and slowly increases her self-esteem. The teacher states that sometimes he is afraid that she will fall again. "Thank you. You're very good. You can go back and sit, okay?" "Yeah, I'm going. I'll sit down. I'm tired. That's the doll again. I was 
up all night. She kept waking me up" "How did she wake you up?" "She was on the shelf and wanted to play with me. But I could not. I shall sleep at night." She starts to talk about how tired she was and she didn't sleep well at night. In contrast, personal hygiene and perception of the whole situation is fixed and remembered several times a day. Unfortunately, V. does not know. "V., go to the toilet. OK? It's a break." "Should I tear the paper?" "Yes, tear a piece of paper and wipe off." "OK Vojto." She goes and plucks a piece of toilet paper, which is as small as a postage stamp. And that's how it goes every day. Always and ever. "V., show me how much paper you tore off." "Look, Vojto, this much. I'm handy." "Yes, you are, but you have to tear a bigger piece." "I see." And then she tears off a larger piece adequate for personal hygiene. V's cognitive area is adequate for her diagnosis, but sometimes there are also moments when, in the various games and word exercises, she is better than her classmates. Despite the extent of mental retardation, she has a fairly good general overview. This is mainly due to spending her free time with adults. "I do not want to leave her alone at home." her mother says. Due to inclusion in the training program - Part 2 - V's schedule does not have trivia areas (reading, writing, numbers). Instead, there are subjects like intellectual education, sensory education, health physical education, craft education, etc. V. is in grade 9 at a special school. In the grade 6, she was reassigned to this training program after examination at the SPC, where she was confirmed, on the basis of teacher's pedagogical findings, that she would never be able to do Part 1, even with IVP (Individual educational plan) in previous years. Intellectual capacity of $\mathrm{V}$ does not allow to acquire the basic areas of trivia (reading, writing, counting). That is why she does not know the letters, only numbers 1, 2, 3 and 4 can be identified. However, the teacher is still attempting to acquire the abbreviation of the position of the letters of her name. While working with the numbers, she works on matching a number to the correct picture, etc. This is very difficult, but V. likes this activity. Any objects sorting is a problem, she cannot focus on the differences, the difficulty is gripping the objects. Once she is shown what to do, she forgets it in the 5 seconds time. In terms of Art, V is very weak, which is caused by disable fine motor skills, especially the grip of the pencils. All her artistic expression is a drawing lines on the spot about $2-5 \mathrm{~cm}$ large. She does not know the colors, so she uses crayons at her choice. But she is very excited about this activity. She is very clumsy in physical education. Literally like a whale on land. However - she enjoys everything. She's very friendly, she gets involved first. She comments: "Hey guys, come on! Hurry up, let's go ..." Everybody knows her. The class attends the local wellness center once a week. V. must be there. She loves water. She has her own life jacket, which she uses instead of a swim ring. In the water she is very happy. She also likes music. She loves children's songs from movies, fairy tales, and serials. She likes singing. As a result of these facts, the teacher states that the main goal of completing compulsory schooling is to enjoy the course. She feels happy with her classmates. She likes them. She likes other teachers too. All teachers from both parts of the school know her. Despite her mental handicap she is very popular.

\subsection{Description of the School Work in Connection with the iPad Mobile Touch Device}

Field of realization of the expected outputs - whereas V. is educated according to the FEP for the field of education at Special Elementary School - Part 2, which has specific areas and expected outputs and also taking in to account how $\mathrm{V}$ expresses herself during the lessons, what difficulty she has in fine motor skills, and especially with regard to what she enjoys, the following criteria have been set by her teacher:

1. Areas of realization of development of visual and auditory perception taking in to account fine motor skills compensation - target of iPad intervention is learning to recognize objects based on visual perception and hearing perception, to classify objects according to established criteria, to distinguish their diversity and to play games that the iPad offers. The aim is to eliminate the teacher's factor as the primary means of achieving the result at the given lesson, while emphasizing the partial autonomy at work.

2. Area of realization of improvement of assembly and dismantling works - apart from the above mentioned facts, V. likes to fold a puzzle. Unfortunately, the choice of the puzzle is very limited and not very affordable. That is why the teacher decided to reinforce the iPad with the intervention of the iPad, according to the valid RFP, taking in to account V's area of interest. 


\section{4 iPad Practice Criteria}

Operation - A short description of how V. responded when first acquainted with the iPad. V. grabbing it in both hands, examining what it is. "What is this? Oh My God, it lights up, what is it? That's how V. responded for the first time. "Teacher, what should I do with it? continued. "Be careful! You see, Fortunately I caught it." The tablet almost fell on the table, nothing could happen, it was in a protective impact of a defensive casing, but the teacher had to react both physically and verbally. $V$., this is a tablet and you have to leave it on the table, okay? We will not pick it up and take it into hands. Tablet? Yes, tablets." She quickly starts tapping her fingers literally everywhere on the screen. "V., wait! You cannot do this. I'll show you something, okay?" "OMG, yeah, OK, show me." speaking with the teacher, who turns on a simple painting application to attract attention from pointless touches. "Look, here you can draw." "Draw? Yeah, this is drawing?" And she takes a crayon from her cup that is on her desk. "No, V., you cannot use crayons. Look, you can use only your finger." And the teacher demonstrates with his finger how finger painting on the touch pad works. Now, from the position of the second person, he holds her forefinger and leads it through the touch layer. You see? You paint. That's great, isn't it? "That's right, this is good," OR. commented their common success. The entire action is accompanied by visible shaking of the whole arms, from the beginning to the palms. Yeah, what is it? It does not work. What is this? The teacher took a moment to look at the other pupils, V. reacting very quickly, pressing the home button that the iPad has at the bottom of the screen. At that moment, she dropped out of the app and touched somewhere else. Of course, another application was running, and V kept touching the screen. "V. what have you done again? You should be drawing. I turned drawing on for you. I was painting. But it does not work. Of course it does not. Because you touched something else, right? And you're somewhere else. Well, she added.

Working with Content-Based Applications - This form of work on the iPad was essentially the only way for $\mathrm{V}$. to implement this device into education. To eliminate the basic use of the iPad, which is not possible thanks to V. specific expression, while working with what the application offers. The teacher has tried the iPad's Assisted Access (AP) feature. It is a feature that can limit the functionality of the iPad, eliminates the interaction of the side buttons and the main home button. The biggest benefit is the direct elimination of the iPad desktop. It means, what I don't want to be used, I simply circle with my finger (make a selection) and this area will remain "dead". The teacher started the painting application that V knew well but always managed to get out of it, activated the AP and gave the iPad to

V. "Come on, you can paint." "I'm coming Vojto, here, shall I paint?" "Yes, you are going to paint the sun now. Try to pick a crayon and paint the sun." Again, she reached for the physical crayon. "No. Not this one. Remember? You cannot use this one! Here is the crayon, here, what is shown here. Can you see it?" "Yeah, I can see it. You don't like it, do you? She adds. V. chose an orange colour. Well, this is fine, try to paint now. The teacher knows that V. will paint a mixture of lines of a certain size, but in the eyes of V. it is a drawing of the sun. That's why he let her paint for some time. Suddenly, he realized there was silence. No one calls him that something goes wrong, etc. In spite of all she kept the 8mins painting before the first comment. "I am finished." "OK, I'm going to look. Wow! You're great. You did it very well. Do you like your painting?" "YES, Oh my God. It hasn't switched! I'm handy?" "You are." That was enough for the day. She painted the sun for now.

Working with creative applications, called App Smashing - does not work for V. At this stage of work with iPads, even the use of Assisted Approach didn't help. This form of work implies that the pupil has certain reading and writing skills. Because of V's potentiality, it was not realistic to get the job done in any application based on her own work. That's why he decided to skip this phase with iPads in the case of V. 


\subsection{Description of the Fulfilment of the School Output according to the Criteria of the FEP Elementary School Special}

\subsubsection{Field of Realization of the Development of Visual and Auditory Perception, taking in to account the Fine Motor Skills Compensation}

The development of visual and auditory perception has placed a great emphasis on the educational field Man and his world. This educational area provides pupils with insights into individual differences, tolerance, appropriate behaviour, mutual assistance and collaboration. Psychic functions develop through sensory perception. The development of individual sensors and sensory analyzers is a prerequisite for the acquisition of this knowledge. In the area of hearing perception, V. should acquire recognition of the individual sounds of living and inanimate nature, match the right sounds to the correct pictures, and orientally identify the sounds of objects of daily necessity. The teacher utilizes Bitsboard Pro for the development of hearing perception. This application allows individual settings for each pupil with special educational needs. He uses this application for $\mathrm{V}$. not only for the development of hearing perception in connection with objects of daily use, the voices of loved ones, but also the sounds of living nature. Due to this application, he can clarify everything that is abstract for $\mathrm{V}$. The whole application works on a learning card basis. He can create them by himself, or he can download ready-made learning cards and add his own voice to them, which is not a prerequisite. "V. Come to me (sitting on the couch), we will explore nature together." "I'm running, teacher" (and walking very slowly). "I will show you pictures on the tablet and you will choose which one is right. The tablet always tells you the name, and you have to match it to the correct picture" "Yeah, it's work again (comments). Look, he shows V. iPad reaction, the card is turned on and you can hear: It is a garden. Now you have to look at the pictures and touch a picture of a garden with your finger. There? No. This is a house. Take a good look. Here. And he points to the garden. Tap it. Yeah, it's right. You see how smart you are. Apart from the teacher's praise, the festive tone of the app will be heard and the image will be properly marked. "Let's go on, he says. It sounds like a forest. V. chooses. OMG, wrong again, comments on herself. $V$., you have to try harder. Yeah fine. She is praised. On the second attempt - well. Now it's the pool. He looks at her and leaves her alone. Cross, cross, and images disappear. The house and swimming pool remain. Click on the house. A cross appears. There is a pool. This is a pool, echoing from the iPad. She marks the last option. A tick appears. Yeah, I'm good. And she tries to make a gesture of success. V., you have to concentrate more. You guess. I do not. You guess. I do not. You guess. Stop it. I saw you. Try to select the first image right. OMG, you want something, again. she commented. That's a bridge, it sounds. V. looks, the finger shakes slightly over the display, but eventually selects the bridge. He lets her work. He needs to be devoted to other pupils. He knows that V. will call him when she finishes with the assisted assault. And indeed after a few minutes, V. says that she is done. Done, teacher, I got it. Okay, I'm going to check it out. She immediately has a summary of the results, so she knows how many times V. hit the first time and how many times she tipped. Everything is color-coded.

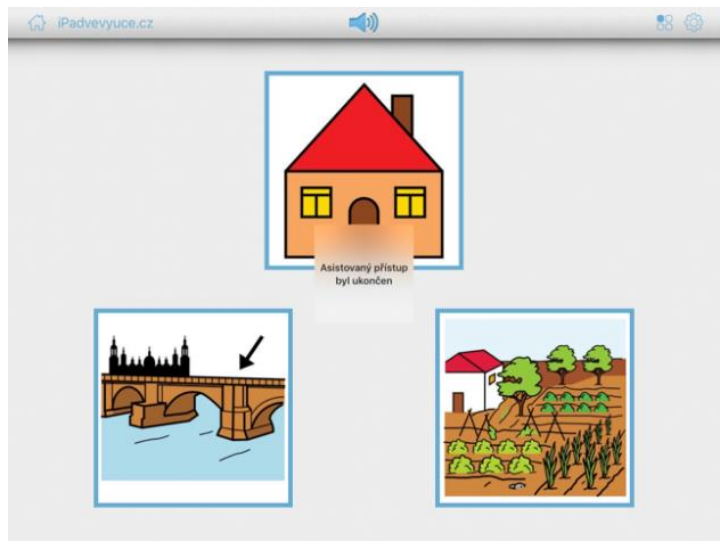

Figure 1. Application Environment in Normal Mode

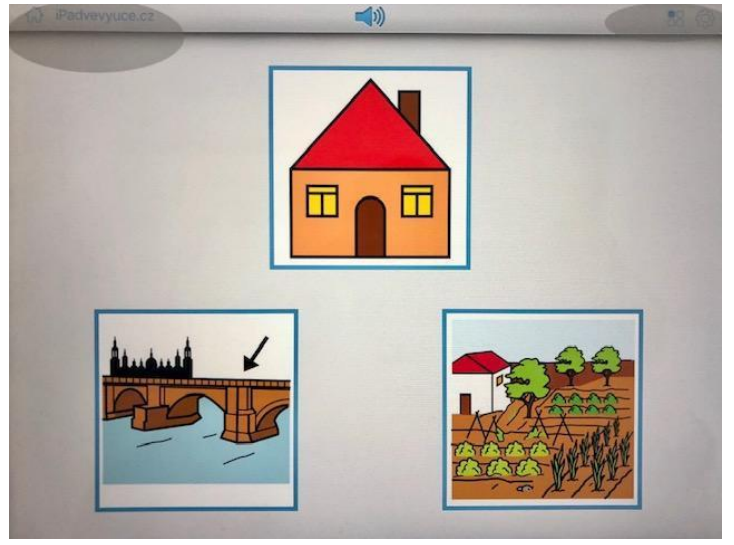

Figure 2. Application Environment with Assisted Access 


\subsubsection{Area of Realization of Improvement of Assembly and Dismantling Work}

Assembly and disassembly are the content of the educational area Man and the world of work. The contents of the curriculum is composed of small sets, composing a puzzle, adding missing parts to the whole, joining elements of the kit (inserting), etc.

This content is realized thanks to the iPad and in addition to a form that the usual jigsaw puzzles do not allow. So, the puzzles for V. are based on what she likes, what she wants. The mosaic that the teacher also uses on the iPad was previously unrealistic. Now, V. can also make mosaics and be very successful, although the composition of one mosaic takes a relatively long period of time. Usually several lessons. That is why the application works in stages. Now, it is very important to mention problems with determining the color of individual mosaic beads. Maybe that's why it takes long time. In spite of this, V is very satisfied with this activity. V., today we are going to make a house. Look. Yeah, that's a house. Should I make a house, teacher? Yes, you are going to make a house. And she is coming to place single-balls to the place, though she is wrong. Damn it! It came back again (in bad color the ball returns to its place). Come here, do not worry. It fled again, she commented. This activity is very entertaining and brings a smile to her face. It seems to be sort of a game, cat x mouse for her. And I got you, here you go. She commands when she can place the right ball.

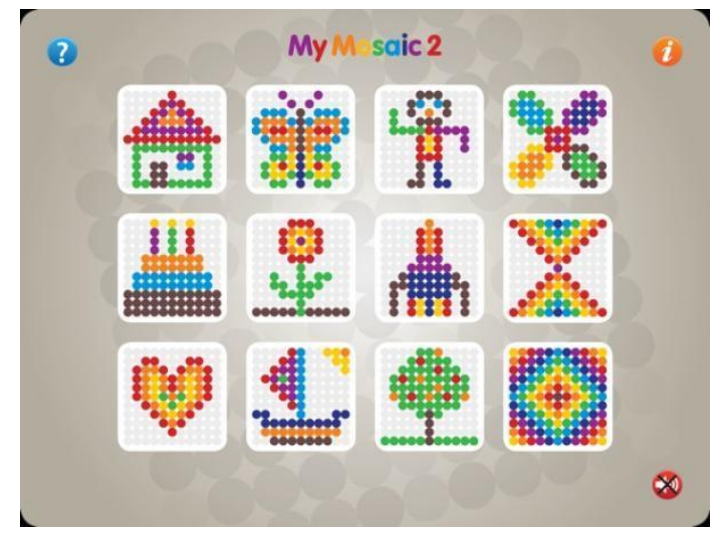

Figure 3. Application environment in normal mode

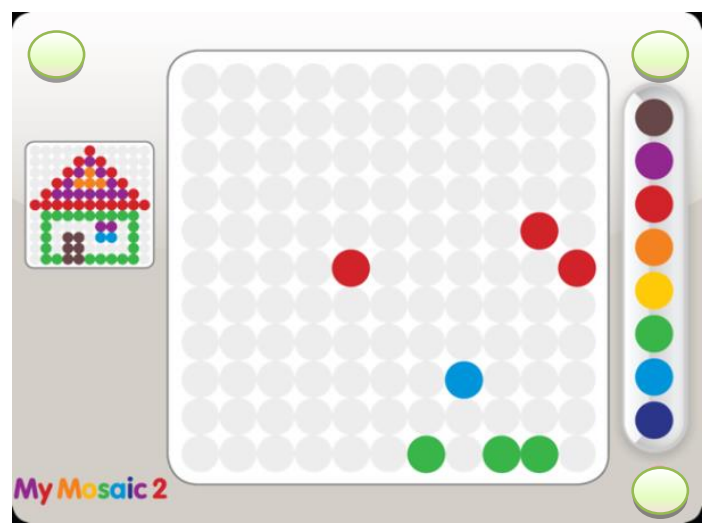

Figure 4. Application environment with Assisted Access

\section{CONCLUSION}

\subsection{Summary of the School Output Fulfilment from a Pupil's Point of View}

\subsubsection{Working with Bitsboard Pro}

Condition - the Assisted Access feature is enabled. V. is able to work independently. The principle of the work must be demonstrated to $\mathrm{V}$ in the first step, it is necessary to know, that she understands the task. For a teacher, it means that he just stays away, watching her working with the iPad. Due to her diagnosis and associated specificities, the entire iPad work appears to be random, respectively - trial and error. Because her attention is very short, it is necessary to repeat the task several times. She needs to play a word several times, till she can understand its meaning, or even she can concentrate on the fact that the sound comes from the loudspeaker. The audiovisual appearance of a well-defined card and the subsequent sense of success she experiences many times, exceeds the fact that it is not always straightforward to know what she is doing and what needs to be done. There are thematic areas and words that are fairly well fixed from home. Therefore, sometimes, according to the auditory stimulus, it is very easy to identify the image that needs to be selected, on the other hand there are situations when she is obviously trying to succeed by trial and error. Here is a big benefit over the typical work with the teacher. In its own use, V. uses sound help, which is much more practical in her work than teacher's help. He would have to stand by her constantly, helping her, and the situation for the other pupils in the classroom would not be entirely satisfactory. 


\subsubsection{Working with My Mosaic 2}

Working on visual mosaics is V.'s interest. Working with dragging beads is fun. There is a great deal of deficiency in color acquisition. V. has a great difficulty in recognizing colors, mostly she selects a wrong color or the correct color by chance. But practically she does not even know what colour the bead really is. Bereaving V. for this activity would be a pity. She really asks for this activity and she is really interested in it.

\section{REFERENCES}

Batorowicz, B., Missiuna, Ca \& Na Pollock. Technology supporting written productivity in children with learning disabilities: A critical review. Canadian Journal of Occupational Therapy, 79 (4), pp. 211-224. 2012.

Aram, D. \& O. Ch. Bar-Arm. Mothers helping their preschool children to spell words: A comparison between interactions using the computer vs. pencil and paper. In International Journal of Child-Computer Interaction, Volume 7, 2016, pp. 15-21, [online]. Feeling. on 30 November 2017. Available on <https://doi.org/10.1016/j.ijcci.2016.03.001>.

Education Queensland Government. iPad in Education, trial report. 2012, [online]. Feeling. on 30 November 2017. Available on 〈http://1url.cz/otXfn>.

SENnet. Tablet computers and learners with special educational needs (case studies: Austria, Belgium, Denmark, Estonia, Italy, Portugal, Turkey), 2014, [online]. Feeling. on 30 November 2017. Available on <http://1url.cz/dt1uf]>.

Flewitt, R., Messer, D. \& N. Kucirkov. New directions for early literacy in digital age: the iPad. Journal of Early Childhood Literacy, 2014. [on-line]. Feeling. on 30 November 2017. Available at <http://journals.sagepub.com/doi/abs/10.1177/1468798414533560>.

Flores, M., Musgrove, K., Renner, S., Hinton, V., Strozier, S. \& A. Franklin. A comparison of communication using the Apple iPad and a picture-based system. Augmentative and Alternative Communication, 28, pp. 74-84, 2012. [on-line]. Feeling. on 30 November 2017. Available on 〈http://dx.doi.org/10.3109/07434618.2011.644579>.

Gybas, V. Assisted Approach. 2016, [online]. Feeling. on 30 November 2017. Available on <https://www.ipadvevyuce.cz/?p=2550>. 